\title{
Comparative environmental and human health evaluations of thermolysis and solvolysis recycling technologies of carbon fiber reinforced polymer waste
}

\author{
Y. F. Khalil, Ph.D., Sc.D. \\ Physical Sciences Department, United Technologies Research Center (UTRC), 411 Silver Lane, \\ East Hartford, CT 06018, USA
}

\section{ABSTRACT}

This quantitative research aims to compare environmental and human health impacts associated with two recycling technologies of CFRP waste. The 'baseline' recycling technology is the conventional thermolysis process via pyrolysis and the 'alternative' recycling technology is an emerging chemical treatment via solvolysis using supercritical water (SCW) to digest the thermoset matrix. Two Gate-to-Gate recycling models are developed using GaBi LCA platform. The selected functional unit (FU) is $1 \mathrm{~kg}$ CFRP waste and the geographical boundary of this comparative LCIA is defined to be within the U.S. The results of this comparative assessment brought to light new insights about the environmental and human health impacts of CFRP waste recycling via solvolysis using SCW and, therefore, helped close a gap in the current state of knowledge about sustainability of SCW-based solvolysis as compared to pyrolysis. Two research questions are posed to identify whether solvolysis recycling offers more environmental and human health gains relative to the conventional pyrolysis recycling. These research questions lay the basis for formulating two null hypotheses $\left(\mathrm{H}_{0,1}\right.$ and $\left.\mathrm{H}_{0,2}\right)$ and their associated research hypotheses $\left(\mathrm{H}_{1,1}\right.$ and $\mathrm{H}_{1,2}$ ). LCIA results interpretation included 'base case' scenarios, 'sensitivity studies,' and 'scenarios analysis.' The results revealed that: a) recycling via solvolysis using SCW exhibits no gains in environmental and human health impacts relative to those impacts associated with recycling via pyrolysis and b) use of natural gas in lieu of electricity for pyrolyzer's heating reduces the environmental and human health impacts by 37\% (lowest) and up to $95.7 \%$ (highest). It is 
recommended that on-going experimental efforts that focus only on identifying the best solvent for solvolysis-based recycling should also consider quantification of the energy intensity as well as environmental and human health impacts of the proposed solvents.

Keywords: Thermolysis; pyrolysis; solvolysis; supercritical water; CFRP waste; EOL waste

\begin{abstract}
Abbreviations
CF: Carbon fibers; CFRP: Carbon fiber reinforced polymer; CTUe: Comparative toxic unit for ecotoxicity impacts such freshwater toxicity; CTUh: Comparative toxic unit for human toxicity impacts; EOL: End of life; EP: Epoxy resin; FU: Functional unit; LCA: Life cycle assessment; LCI: Life cycle inventory; LCIA: Life cycle impact assessment; nCF: Neat carbon fibers; NG: natural gas; PAN: Polyacrylonitrile; rCF: Recycled carbon fibers; RQ: Research question; SCF: Supercritical fluids; SCW: Supercritical water; TRACI 2.1: Tool for Reduction and Assessment of Chemicals and Other Environmental Impacts; TRL: Technology readiness level; vCF: Virgin carbon fibers.
\end{abstract}




\section{Introduction}

\subsection{Background}

Global consumption of carbon fiber reinforced polymer (CFRP) continues to increase and is estimated to reach $\approx 209,800$ tons by 2020 (Yuyan et al., 2009; McConnel, 2010; Witik et al., 2013; La Rosa et al. 2016; Das et al., 2016; Li et al., 2016; Pillain et al., 2017, Meng et al., 2017). This lightweight structural material has many industrial applications including commercial and military aircraft, automotive, electronics, construction, sporting goods, etc. (Khalil, 2017). Another CFRP application is manufacturing CF-based Type-III and Type-IV tanks (Khalil et al., 2009; Khalil et al., 2010) for on-board vehicular hydrogen storage (whether H2 is stored as compressed gas or in solids-state forms such as metal hydrides, chemical hydrides, or adsorbed on activated carbon). For the commercial aircraft industry, good cases in point which demonstrate use of CFRP are Airbus A350XWB and Boeing 787 Dreamliner (Pimenta and Pinho, 2011; Yang et al., 2012; Ye and Bounaceur, 2013; Shuaib et al., 2015), where $\approx 50 \%$ of the aircraft weight is composite. Use CFRP in unmanned aerial vehicles (UAV) is an example of how the military leverages this lightweight structural material. Demand for carbon fiber (CF) in the aerospace defense sector is forecasted to reach 18,462 tons by 2020 compared to 7,694 tons in 2011 (Robert, 2017).

Current estimates show that $\approx 3,000$ tons of CFRP waste are generated annually in Europe and the U.S. (Vicki, 2010; Ye et al., 2013; Shuaib et al., 2015). Sources of this waste include tows cuttings during manufacturing, expired prepregs during storage, and EOL CFRP components. Literature data (Lester et la., 2004) shows that waste from tows cutting could be as high as $40 \%{ }^{1}$ Moreover worldwide, $\approx$ 8,500 commercial aircraft are expected to retire and dismantled by 2025 (Carberry, 2008; McConnel, 2010). In this regard, Yang et al. (2012) noted that the aerospace

\footnotetext{
${ }^{1}$ Vartega Carbon Fiber Recycling, December 2016.
} 
industry alone is estimated to reclaim between 4.5 to 6.8 million $\mathrm{kg}$ of rCF (both from manufacturing and EOL) by 2029.

The forecasted rise in CFRP waste generation signals an urgent need for identification of sustainable technologies to process the anticipated thousands of tons of CFRP waste. Subsection 1.2 summarizes current and emergent methods for managing CFRP waste.

\subsection{Literature review}

The published literature covers numerous studies on waste management of CFRP manufacturing waste and EOL components. The reported waste management approaches include landfilling, incineration (with and without heat recovery) and recycling (Shuaib et al., 2015; Khalil, 2017. Historically, CFRP waste has been disposed of in landfills but since 2004 both the U.S. Environmental Protection Agency (EPA), Land Disposal Restrictions (LDR), and European regulation (EU Directive 99/31/EC) continued to impose constraints on disposal of organic materials (like CFRP) in landfills (Shuaib et al., 2015; La Rosa et al., 2016; Roux et al., 2017; Meng et al, 2017). Aircraft manufacturers are anticipating future regulations on aircraft EOL composite waste disposal in a manner similar to current regulatory restrictions on CFRP waste from scrapped vehicles. Incineration of composite waste has its own environmental problems and, thus, is viewed as an unsustainable solution. Additionally, high cost and high energy intensity of CF production from the Pan-based precursor (Shuaib et al., 2015; Khalil, 2017) has driven the need for recycling of CFRP waste. In this regard, numerous studies have reported on CF recycling technologies including microwave heating (Lester et al., 2004; Shuaib et al., 2015; Khalil, 2017), pyrolysis (Cunliffe et al., 2003), hydro-thermolysis (Pinero-Hernanz et al., 2008), chemical solvolysis (Pinero-Hernanz et al., 2008; Goto, 2009). Those studies among others reached the same 
conclusion that recycling CF from manufacturing waste and EOL CFRP components has environmental and economic benefits.

The CFRP waste recycling approach includes mechanical recycling, thermolysis, and solvolysis using supercritical fluids (SCFs) ${ }^{2}$ like water, alcohols (e.g., methanol, ethanol, npropanol, etc.), and other organic solvents (such as acetone and acetic acid) under different operating temperatures and pressures (Pimenta and Pinho, 2011; La Rosa, 2016; Khalil, 2017).

Mechanical recycling involves CFRP waste grinding and sieving to separate CF from the resin matrix (Howarth, 2014; Oliveux et al, 2015; Shuaib et al., 2015). The associated source of environmental and human health burdens comes from the electrical energy (MJ/kg CFRP waste) expended in the grinding and sieving processes. Because mechanical recycling is out of scope of the current research, it will not be further discussed in the remainder of this section in order to focus only on recycling via thermolysis and solvolysis using supercritical water (SCW).

Thermolysis involves thermal decomposition of the thermoset resin matrix to recover CF (Cunliffe et al, 2003; Pickering, 2006; Song et al., 2009; Pompidou et al., 2012; Yang et al., 2012; Greco et al, 2012; Morin et al., 2012; López et al., 2013; Witik et al., 2013). Song et al. (2009), for example, reported that $\approx 2.8 \mathrm{MJ}$ of energy would be needed to pyrolize $1 \mathrm{~kg}$ of CFRP waste and that $\approx 19 \mathrm{MJ} / \mathrm{kg}$ CFRP waste could be recovered from pyrolysis’s recyclate byproducts. Witik and his research team (2013) reported that use of pyrolysis to recover CF from CFRP waste would consume $\approx 5$ to $10 \%$ of the energy required to produce neat $\mathrm{CF}$ (nCF). Applying this insight to Khalil’s (2017) estimated energy consumption of 301.3 MJ to produce 1 kg CFRP (60 wt\% CF),

\footnotetext{
${ }^{2}$ A supercritical fluid (SCF) is a substance at temperatures and pressures above its critical point, where distinct liquid and gas phases do not exist and where the liquid and gas phases disappear to become a single supercritical phase. SCFs effuse through solids just like a gas, dissolve materials just like a liquid, and have characteristics that are useful in many industrial applications including digesting the polymeric resin matrix in CFRP waste.
} 
the energy required to produce $1 \mathrm{~kg}$ rCF via pyrolysis would range from 15 to $30 \mathrm{MJ} / \mathrm{kg} \mathrm{rCF}$. Moreover, studies on microwave heating of CFRP (Lester et al., 2004; Shuaib et al., 2015; Obunai, et al. (2015) reported this emerging technology is technically feasible, more energy efficient, and faster compared to the conventional thermolysis. Lester et al. (2004) reported that microwave heating would require about $10 \mathrm{MJ} / \mathrm{kg}$ of CFRP which less than the energy required for conventional pyrolysis (without heat recovery) by about 33\% less that the energy required for conventional pyrolysis (Shuaib et al., 2015). However, neither Lester et al. (2004) nor Shuaib et al. (2015) have commented on the cost of the microwave recycling technology. With respect to the tensile strength of rCF, microwave heating can retain about $79 \%$ of the fiber's original tensile strength compared to about 96\% for conventional pyrolysis technology (Shuaib et al., 2015).

Thermolysis via Pyrolysis is done by heating the CFRP waste in an inert environment such as nitrogen $\left(\mathrm{N}_{2}\right.$ ) at temperatures between $400^{\circ} \mathrm{C}$ and up to $800^{\circ} \mathrm{C}$ (Pickering, 2006). Pyrolysis also produces byproduct recyclates, namely, gases (such hydrogen, methane, and other noncondensable hydrocarbons), oils and wax (the condensable byproduct), and carbonaceous solid residue (char). The liquid byproduct has a relatively high caloric value (embodied energy) similar to fuel oil ( $\approx 30$ to $40 \mathrm{MJ} / \mathrm{kg}$ ) and the gaseous byproduct has a relatively lower calorific value $\approx 15$ to $20 \mathrm{MJ} / \mathrm{kg}$ (Pickering, 2006). Nunes (2017) examined CFRP waste recycling via thermolysis using steam and nitrogen gas by a process developed in France. They used $1.4 \mathrm{~kg} \mathrm{~N} \mathrm{~N}_{2}$ gas and 1.6 $\mathrm{kg}$ water (steam) to treat $1 \mathrm{~kg}$ of CFRP waste. The total electric energy consumption in this process was $71.64 \mathrm{MJ}(\approx 20 \mathrm{kWh})$ per $\mathrm{kg}$ CFRP waste. Their LCIA results showed environmental advantages comapred to waste landfilling. 
Recycling CFRP using the gasification technology (Ye and Bounaceur, 2013) involves using superheated steam at about $600^{\circ} \mathrm{C}$ at atmospheric pressure. The authors reported that this technology is efficient in remocing the epxoy resin used in CFRP. Their observation was based on a bench-scale experimental investigation. As a mild ocident, suprheated steam decomposes the polymer matrix into low molecular weight hydrocarbons with emission of gases including CO, CO2, H2 and CH4 (Ye and Bounaceur, 2013). The authors judged, based on their experimental observations, that this technology could be technically and economically feasile. However, they arrived at this conclusion without providing a regurous scaling-up study from their bench-scale results to a typical industrial setting.

Researchers like Pinero-Hernanz et al. (2008), Yuyan et al. (2009), Morin et al. (2012), Knight (2013), Pinçaud et al. (2014), Yildirir et al. (2014), Dauguet et al. (2015), Henry et al. (2016), La Rosa et al. (2016), Keith et al. (2016), and Okajima and Takeshi (2017) had experimentally examined CFRP waste solvolysis using SCFs as solvents to digest the thermoset resin into liquidphase depolymerized monomers. The removal efficiency of the resin matrix could be $\geq 98 \%$ (Pinero-Hernanz et al., 2008) and Yuyan et al. (2009) reported 100\% decomposition efficiency of the thermset resin using SCW. The operating temperature and pressure of this chemical treatment are above the critical temperature $\left(\mathrm{T}_{\mathrm{C}}\right)$ and critical pressure $\left(\mathrm{P}_{\mathrm{C}}\right)$ of the solvent. For example, water has $\mathrm{T}_{\mathrm{C}}=374^{\circ} \mathrm{C}$ and $\mathrm{P}_{\mathrm{C}}=22 \mathrm{MPa}$ and, hence, $\mathrm{SCW}$ should be at temperatures and pressures above $374.1^{\circ} \mathrm{C}$ and $22 \mathrm{MPa}$ (Knight, 2013). In the case of using SCW as the solvent, the resulting liquid waste byproduct should contain a mixture of water and organics from the depolymerization of the thermoset resin. When chemical treatment of CFRP waste involves use of supercritical alcohols such as methanol, ethanol, and n-propanol, the operating temperatures may range from $300^{\circ} \mathrm{C}$ to $450^{\circ} \mathrm{C}$ and the operating pressure may range from $5 \mathrm{MPa}$ to $17 \mathrm{MPa}$ (Yang et al., 2012). Some 
researchers proposed use of acids to dissolve the thermoset matrix, for example, LaRosa et al. (2016) chemically treated CFRP waste with acetic acid (25 vol\% solution at $85^{\circ} \mathrm{C}$ for 1.5 hours) to reclaim the reinforcing CF from the polymer matrix. Depolymerization of the thermoset resin in CFRP waste was also carried out in ethylene glycol and ethylene glycol/water mixtures at nearcritical conditions of the two solvents (Yildirir et al., 2014). Currently, however, solvolysis using SCFs remains in early stages of development and (Shuaib et al., 2015; Rybicka, 2016) assigned this chemical treatment technology as a low technology readiness level (TRL 2 to 4) compared to thermolysis which is a more matured technology (i.e., high TRL level in the range 8 to 9). Recycling via solvolysis also faces other technical challenges including high cost and material compatibility issues due to their highly corrosive nature (Yuyan et al., 2009).

Life cycle impact assessment (LCIA) studies reported in the published literature were limited to comparing the environmental burdens and human toxicity of various thermolysis processes (namely, pyrolysis and fluidized beds) versus landfilling and incineration with and without heat recovery (Bjorklund and Finnveden, 2005). For example, Witik et al. (2013) compared the environmental viability of recycling via pyrolysis against incineration and landfilling. Pinçaud et al. (2014) is the only research team who compared the environmental burdens of CFRP waste recycling via solvolysis using SCW versus landfilling. Their study concluded that the solvolysis process is greener despite the associated high electricity consumption (assumed to be dominated by nuclear power). Moreover, Pinçaud et al. (2014) did not report either the amount of electrical energy (MJ) needed to produce $1 \mathrm{~kg}$ of SCW, or SCW mass required per $1 \mathrm{~kg}$ CFRP waste. Finally, the study did not discuss the technical challenge associated with material compatibility issues as SCW is known to be a highly corrosive reaction medium. Moreover, in our opinion, use of landfilling as a benchmark in those comparative LCIA studies is not scientifically sound since 
thermoset polymers are generally non-biodegradable and may require hundreds of years to gradually biodegrade and release greenhouse gases (GHG) like methane. In this regard, Witik and his research team (2013) had to assume a 1\% degradation rate over the first 100 years of CFRP waste disposal in landfills and other studies assumed $\approx 26 \%$ degradation of 60,000 years. Hence, deriving conclusions based on benchmarking against CFRP waste disposal in landfills is subjective and dependent on assumptions made (Witik, et al., 2013).

La Rosa et al. (2016) used acetic acid-water binary solution ( $25 \mathrm{wt} \%$ acetic acid) at $80^{\circ} \mathrm{C}$ to recover CF from waste CFRP. Their chemical treatment seems to be less energy intensive compared to recycling via solvolysis using CCFs. In our research, we applied GaBi LCA platform to model the recycling process employed by La Rosa et al. (2016). Our LCIA calculations showed that the cradle-to-gate primary energy consumption to produce $1 \mathrm{~kg}$ of acetic acid-water binary solution (25 wt\% acetic acid) is about $42.16 \mathrm{MJ}$. Also, about $2.37 \mathrm{~kg}$ CO2-Equiv would be emitted to produce $1 \mathrm{~kg}$ acetic acid-water binary solution at $80^{\circ} \mathrm{C}$. Since La Rosa et al. (2016) used $1 \mathrm{~kg}$ acetic acid solution (25 wt\% acetic acid) per $0.577 \mathrm{~kg}$ CFRP, we calculate $1.73 \mathrm{~kg}$ acetic acid solution to treat $1 \mathrm{~kg}$ CFRP, which will lead to emission of $4.1 \mathrm{~kg}$ CO2-Equiv/kg-CFRP. Accordingly without performing cradle-to-gate LCIA calculations, it might seem that the energy required to perform low-temperature solvolysis using acetic acid-water solution is relatively low.

The gap analysis performed in this research revealed that: a) Current published literature lacks detailed comparative LCIA-based environmental and human health impacts assessment of the emerging solvolysis-based technologies for recycling CFRP waste and b) There is a crucial need for determining which among several recycling technologies offers the least environmental and human health burdens. 


\section{Research problem statement, objective, and originality}

\subsection{Problem statement}

As a result of growing annual global consumption of CFRP, thousands of tons of CFRP waste are anticipated to be generated annually from several industries, including the aerospace, automotive, and wind turbine industries. Managing CFRP waste by landfilling is facing continued regulatory restrictions, and incineration is viewed as an unsustainable practice. Also, CF is conventionally manufactured from a costly petroleum-based precursor called polyacrylonitrile (PAN) through an energy intensive process (Khalil, 2017). Accordingly, recycling CFRP waste is considered to be the optimal waste management strategy. Presently, there is a crucial need for determining which among several recycling technologies offers the least environmental and human health burdens. LCIA appears to be the appropriate methodology to address this central sustainability question.

\subsection{Objective}

The objective of this research is to employ LCIA quantitative methods and tools to compare the environmental and human health impacts associated with the two CFRP waste recycling technologies, namely, conventional thermolysis via pyrolysis (i.e., thermal decomposition in an inert environment) and the emerging solvolysis technology which uses supercritical water (SCW) to chemically digest the thermoset polymer matrix contained in CFRP waste.

\subsection{Originality and impact}

Our gap analysis of relevant published literature revealed, to the best of our knowledge, the current lack of the following: a) A comprehensive and quantitative environmental and human health impacts assessment which compares the conventional pyrolysis technology vs. emerging solvolysis recycling technology of CFRP waste, b) Identification of which among several recycling 
technologies offers the least environmental and human health burdens, and c) Reporting the energy intensity and technical challenges associated with use of SCFs to depolymerize the thermoset resin matric and recover CF. In this regard, it is worth mentioning that the relevant published work on recycling via solvolysis have invariably highlighted only merits of solvolysis in terms of producing cleaner rCF (compared to the pyrolysis process which may leave some char residue on rCF) and improved mechanical properties of the recovered CF. Unfortunately, nothing was reported to the energy intensity associated with producing those SCFs (such as SCW).

The originality of this research are three-fold as follows:

- Performance of comparative environmental and human health impacts assessment of CFRP waste recycling via pyrolysis (which is the conventional and matured technology) vs. emerging recycling via solvolysis using supercritical water (SCW).

- Adoption of a comprehensive approach to LCIA results interpretation by including not only the base case scenarios, but also include sensitivity studies (SS) and scenarios analysis (SA). Inclusion of SS and SA in interpreting LCIA quantification results is critically important as it helps addressing uncertainties associated with both primary and secondary data used in the developed recycling models.

- Identification of where additional research efforts should be directed with respect to solvolysis using SCFs for CFRP waste recycling.

\section{Research impact}

The insights gained from this research help close a gap in the current state of knowledge about sustainability of SCW-based solvolysis as a recycling technology for CFRP waste and how it compares to recycling via pyrolysis. 


\section{Research methodology}

The adopted research methodology is composed of two steps that guided this comparative assessment. These two steps are:

- Formulation of the research questions.

- Hypothesis testing.

\subsection{Research questions (RQs)}

The following two research questions are formulated to address sustainability of CFRP waste recycling via solvolysis using SCW:

a) To what extent is solvolysis more environmentally sustainable compared to thermal recycling?

b) To what extent is solvolysis safer from the human health perspective compared to thermal recycling?

\subsection{Hypothesis testing (HT)}

Having formulated the aforementioned RQs, hypothesis testing methodology is then applied to translate each of the proposed research questions into an equivalent null hypothesis (denoted as $\mathrm{H}_{0}$ ) and an associated alternative hypothesis (denoted as $\mathrm{H}_{1}$ ). The null hypothesis states a specific claim that is assumed to be true unless there is a strong evidence against it. The research (or alternative) hypothesis articulates a new claim that can be accepted if the researcher can provide evidence to support this claim.

Based on the RQs established in Subsection 3.1, two null hypotheses $\mathrm{H}_{0,1}$ and $\mathrm{H}_{0,2}$ ) and two research hypotheses $\left(\mathrm{H}_{1,1}\right.$ and $\left.\mathrm{H}_{1,2}\right)$ are formulated as follows: 


\section{Null hypothesis $\left(\mathrm{H}_{0,1}\right)$ :}

Solvolysis-based recycling of CFRP waste does not offer reduction in environmental impacts relative to those associated with thermal recycling.

\section{Research hypothesis $\left(\mathrm{H}_{1,1}\right)$ :}

Solvolysis-based recycling of CFRP waste could offer reduction in environmental impacts relative to those associated with thermal recycling.

\section{Null hypothesis $\left(\mathrm{H}_{0,2}\right)$ :}

Solvolysis-based recycling of CFRP waste does not reduce adverse human safety impacts relative to those associated with thermal recycling.

\section{Research hypothesis $\left(\mathrm{H}_{1,2}\right)$ :}

Solvolysis-based recycling of CFRP waste could reduce adverse human safety impacts relative to those associated with thermal recycling.

If the provided evidence supports the claim made by the two research hypotheses, then the posed claim should be accepted. Otherwise, the research hypotheses should be rejected in favor of the claim made by the null hypotheses. It should be noted that whether claims made by the research hypotheses are accepted or rejected, new insights are generated that can help advancing current state of knowledge about the topic being investigated. The generated insights should be used by the researcher to shed new light on where additional research efforts and funding should be directed.

\subsection{LCA methods and tools}

The LCA methodology is an internationally recognized approach described in ISO Standards 14040-2006 and ISO 14044-2006 (Bovea and Vidal, 2004; Khalil, 2017). The LCA quantitative 
tool being employed in this investigation is the GaBi platform, ${ }^{3} \mathrm{GaBi}$ thinkstep life cycle inventory (LCI) databases, ${ }^{4}$ and TRACI 2.1 LCIA methodology. ${ }^{5}$

LCA methods and tools have been employed to generate quantifiable evidence that can either support or reject the claims of the proposed $\mathrm{H}_{1,1}$ and $\mathrm{H}_{1,2}$. If the quantifiable evidence fails to support the claims of $\mathrm{H}_{1,1}$ and $\mathrm{H}_{1,2}$, then claims made by $\mathrm{H}_{0,1}$, and $\mathrm{H}_{0,2}$ should be accepted and vice versa. Rejection of claims of $\mathrm{H}_{1,1}$ and $\mathrm{H}_{1,2}$ is equally valuable to the case of accepting these claims since in both cases new scientific insights are revealed to help closing the identified knowledge gap about the environmental and human health impacts associated with emerging vs. conventional recycling technologies of CFRP waste.

\subsection{LCA recycling models (i.e., product systems) and assumptions}

Two CFRP waste recycling models are developed using GaBi LCA platform. These models and their system boundaries are shown in Figs. 1 and 2. As can be seen, the scope of this comparative assessment excludes other life cycle phases, namely, CFRP production phase and use phase. Fig. 1 shows two input mass flows (CFRP waste and N2 gas to provide the inerting environment inside the pyrolyzer). The two input energy flows represents the electricity required for CFRP waste grinding and either electricity or natural gas to heat the pyrolyzer and its content to the required temperature. The output mass flows (recyclates) represent rCF, pyrolysis gases (containing hydrogen, methane, and other hydrocarbon gases), oils \& wax, and carbonaceous solid

\footnotetext{
${ }^{3} \mathrm{GaBi}$ ts LCA platform. Source: http://www.gabi-software.com

${ }^{4} \mathrm{GaBi}$ databases 2017 edition. Source: http://www.gabisoftware.com/uploads/media/GaBi_Databases_2017_Upgrades_and_Improvements.pdf

${ }^{5}$ Bare, J.C. (2012). Tool for the Reduction and Assessment of Chemical and Other Environmental Impacts (TRACI), Version 2.1. User’s Manual; EPA/600/R-12/554 2012.
} 
residue (char). In theory, the pyrolysis gases could be used as fuel to heat the pyrolyzer and, hence, could offset some of the electricity (or natural gas) energy required for pyrolyzer's heating. Also, the oils \& wax could be used as fuels or as feedstock for manufacturing other chemicals. However, these options are not included in this study.

Fig. 1. Model for CFRP waste recycling via pyrolysis.

Fig. 2 shows two input mass flows (CFRP waste and deionized water to provide SCW). The two input energy flows represent the electricity required for CFRP waste grinding and to operate the pumps and compressors to produce steam at the required supercritical pressure. Also, natural gas burning is required to produce steam from the deionized feedwater. The output mass flows (recyclates) represent rCF, liquid-phase mixture of organic monomers (from depolymerizing the thermoset resin) mixed with water, and carbonaceous solid residue (char). In theory, the monomers could be further treated to produce useful chemical products. However, this possibility is not included in the current study.

Fig. 2. Model for CFRP waste recycling via solvolysis using SCW.

Finally, the following assumptions have been made and applied to the recycling models (Figs. 1 and 2):

- Recycling facility is located at the same site where CFRP waste is collected. The deliberate Exclusion of CFRP waste transport to the recycling facility is intended to avoid introducing sources of subjectivity into this study. To be included into the recycling models, the transport 
distance and transport type between CFRP waste collection site and recycling facility will have to be subjectively assumed.

- Recycling facility is geographically located within the U.S. Hence, the electricity required for recycling (input energy flows in Figs. 1 and 2) is assumed to be provided by the U.S. grid electricity mix. Similarly, the thermal energy production via natural gas burning (input energy flows in Figs. 1 and 2) is assumed to be in the U.S. It should be noted that the U.S. electricity grid mix is represented by a portfolio of $20 \%$ nuclear, $65 \%$ fossil (of which $30 \%$ from coal, $34 \%$ from natural gas, and $1 \%$ from oil) and $15 \%$ renewables. ${ }^{6}$

- CFRP waste is assumed to contain $60 \mathrm{wt} \% \mathrm{CF}$ and $40 \mathrm{wt} \%$ thermoset (epoxy resin) matrix.

- CFRP waste recycling via thermolysis without energy recovery has been considered in this study.

- The emerging recycling via solvolysis using SCW as a solvent is considered to be the alternative scenario for rCF production.

- Sources of CFRP waste include expired and/or off-cutting manufacturing prepregs and EOL CFRP components.

- Materials of construction of the two recycling facilities (pyrolysis and solvolysis) are not taken into account in the recycling models. This assumption has been made to avoid another source of uncertainty in LCIA calculations.

\footnotetext{
${ }^{6}$ GaBi LCI database for U.S. electricity grid mix and the U.S. Energy Information Administration at www.eia.gov.
} 
3.5 LCA Functional unit (FU)

Per ISO Standards 14040 and 14044, studies that use LCA methods should define a functional unit (FU) upon which LCIA calculations are based. In this research, the selected FU for the baseline scenario and alternative scenario is $1 \mathrm{~kg}$ of CFRP waste. The choice of this mass-based FU is intended to make the assessment results easily scalable.

\subsection{Life cycle inventory (LCI): sources of primary and secondary data}

Input mass and energy flows as well as output flows (recyclates) for the two recycling models (Figs. 1 and 2) are shown in Tables 1 and 2. The primary data are extracted from the relevant literature sources as noted in Tables 1 and 2 and the secondary data which represent the input energy flows (Figs. 6 and 7) are taken from GaBi LCI databases.

\section{Table 1}

Primary and secondary data for thermolysis (via pyrolysis) model (Fig. 1).

\section{Table 2}

Primary and secondary data for solvolysis model (Fig. 2).

\section{Results and discussion}

The comparative LCIA is carried out using GaBi software platform and TRACI 2.1 database. The mid-point impact categories being calculated in this comparative assessment are: acidification [kg SO2-Equiv], ecotoxicity [CTUe], eutrophication [kg N-Equiv], global warming [kg CO2Equiv], human health-particulates [kg PM2.5-Equiv], human toxicity-carcinogenics [CTUh], human health-non-carcinogenics [CTUh], ozone depletion [kg CFC 11-Equiv], and smog [kg O3Equiv]. 


\subsection{Recycling via pyrolysis}

\subsubsection{Base case scenario}

The pyrolysis base case scenario assumes $0.53 \mathrm{MJ} / \mathrm{kg}$ CFRP waste for the grinding energy and $12 \mathrm{MJ} / \mathrm{kg}$ CFRP waste for pyrolyzer's heating using NG. The sources of these primary data are depicted in Table 1.

Fig. 3 shows the calculated mid-point impact categories using TRACI 2.1 LCIA methodology. Two observations are to be noted in this figure. Firstly, the $\mathrm{Y}$-axis is plotted using a logarithmic scale in order to include values of all the impact categories and secondly, the plotted impact categories have different units as shown on the $\mathrm{x}$-axis. For example, the carbon footprint (signified by global warming) associated with this scenario is $\approx 0.96 \mathrm{~kg}$ CO2 equiv. per $\mathrm{kg}$ CFRP waste and ecotoxicity is $\approx 0.03$ CTUe units per kg CFRP waste.

Fig. 3. Base case pyrolysis scenario (0.53 MJ grinding energy and $12 \mathrm{MJ}$ thermal energy from NG). Calculations are per 1 FU, i.e., 1 kg CFRP waste.

Another key takeaway is that the energy required to recover $1 \mathrm{~kg}$ rCF using pyrolysis (with NG for pyrolyzer's heating) is $\approx 5.5 \%$ (if NG is used for pyrolyzer's heating) and $\approx 11.7 \%$ (if electricity is used for pyrolyzer's heating) of the energy required to produce $1 \mathrm{~kg}$ nCF from PAN precursor (Khalil, 2017).

\subsubsection{Sensitivity studies (SS)}

Grinding energy (mechanical size reduction) has been selected as the sensitivity parameter due to the associated wide range of values $(0.27$ to $2.03 \mathrm{MJ} / \mathrm{kg}$ with an intermediate value of 0.53 
MJ/kg CFRP waste cited in the published literature for this parameter (Witik et al., 2013; Howarth et al., 2014; Meng et al., 2017).

Fig. 4 displays the pyrolysis sensitivity study using grinding energy as the sensitivity parameter. The origin point $(0 \%, 0 \%)$ in Fig. 4 represents the case where the grinding energy is $0.53 \mathrm{MJ} / \mathrm{kg}$ CFRP waste (i.e., base case scenario). It is assumed that the pyrolyzer is heated by NG as recommended in this research. As Fig. 4 shows, ozone depletion is the most sensitive impact category (line with the steepest slope) to changes in the grinding energy followed by human health (particulates). The ecotoxicity category is the least sensitive category (line with the lowest slope) to changes in the grinding energy. The key insight that can be obtained from this sensitivity study is that use of energy-efficient grinding equipment (which consumes less than $0.53 \mathrm{MJ} / \mathrm{kg}$ CFRP waste) can have a major impacts on reducing the ozone depletion category.

Fig. 4. Pyrolysis sensitivity study: grinding energy as the sensitivity parameter.

Legend: 1) Ozone depletion [kg CFC 11-Equiv.], 2) Human health, particulates [kg PM2.5Equiv.], 3) Acidification [kg SO2-Equiv.], 4) Eutrophication [kg N-Equiv.], 5) Human toxicity, non-carcinogenics [CTUh], 6) Human toxicity, carcinogenics [CTUh], 7) Smog [kg O3-Equiv.], 8) Global warming [kg CO2-Equiv.], and 9) Ecotoxicity [CTUe].

\subsubsection{Scenarios analysis (SA)}

TRACE 2.1 LCIA methodology for environmental and human health impacts are compared for the following two scenarios: 
- Pyrolyzer is electrically heated (Morin et al., 2012; Yang et al., 2012; Witik et al., 2013) using the U.S grid mix.

- Pyrolyzer is heated via NG burning as proposed in this research.

Based on the comparative impact assessment results shown in Fig. 5, use of NG heating in lieu of U.S. electricity mix for pyrolyzer’s heating would lead to $\approx 95.7 \%$ reduction on ozone depletion (highest), followed by $\approx 91.6 \%$ reduction in human health (particulates), and $\approx 37 \%$ reduction in ecotoxicity (lowest). The reduction in carbon footprint (global warming) is $\approx 55.4 \%$.

Fig. 5. Scenarios analysis: Pyrolyzer's heating using U.S. electricity grid mix vs. natural gas (calculations per 1 FU, i.e., 1 kg CFRP waste).

\subsection{Recycling via solvolysis using SCW}

When water is compressed and heated to pressures and temperatures above its critical point $\left(\mathrm{P}_{\mathrm{C}}=22.1 \mathrm{PMa}\right.$ and $\left.\mathrm{T}_{\mathrm{C}}=374^{\circ} \mathrm{C}\right), \mathrm{SCW}$ is produced. Under such conditions, SCW becomes an excellent solvent with viscosities, densities and other physical properties that are intermediate between those of its gaseous and liquid states. Good heat-transporting properties and high diffusivity are among the desired properties of SCW (Loppinet-Serani et al., 2008). Moreover compared to other SCFs (like methanol, ethanol, n-propanol, acetone, acetic acid, nitric acid, and ethylene glycol), water is thought to be a greener reaction medium that is abundant and less costly, and have no toxic effects. The aforementioned desired properties of SCW support our rationale for selecting SCW as the solvent that can efficiently digest the thermoset resin matrix in CFPF waste. Nonetheless, as this research reveals, production of SCW is an energy intensive process with adverse environmental and human health impacts that exceed those impacts associated with recycling CFRP waste via pyrolysis. 


\subsubsection{Base case scenario}

The calculated values of environmental and human health impact categories of solvolysis using SCW base case scenario are plotted in Fig. 6. Note that in order to plot all the values of these impact categories, a logarithmic scale is used for the Y-axis. All calculations are based on 1 FU (i.e., $1 \mathrm{~kg}$ CFRP waste). According to Fig. 6, $\approx 16.2 \mathrm{~kg} \mathrm{CO2-Equiv} \mathrm{is} \mathrm{emitted} \mathrm{per} \mathrm{kg}$ of CFRP waste being chemical treated by the emerging solvolysis using SCW technology.

Fig. 6. Impact categories associated with solvolysis using SCW: base case scenario. (Calculations based on 1 FU, i.e., 1 kg CFRP waste).

\subsubsection{Sensitivity studies (SS)}

Two sensitivity studies, SS-1 and SS-2, are performed for the SCW-based solvolysis technology. The selected sensitivity parameter for SS-1 is the electrical energy (25 MJ) used for operating the pumps and compressors associated with production of $4.67 \mathrm{~kg}$ SCW required for depolymerizing 1 kg CFRP waste (Knight, 2013; Dauguet et al., 2015). Appendix (A) provides more details on SCW production.

The x-axis in Fig. 7 shows percent changes in the electrical energy in the positive and negative directions around the origin point $(0 \%, 0 \%)$. The y-axis shows the corresponding percent change in the calculated environmental and human health impacts in response to changes in the x-axis. As can be seen from Fig. 7, the most sensitive impact category to changes in the electrical energy (line with steepest slope) is human health, particulates [kg PM2.5-Equiv.] followed by ecotoxicity [CTUe] and acidification [kg SO2-Equiv.]. The least sensitive parameter to changes in the electrical energy (line with lowest slop) is global warming [kg CO2-Equiv.]. The main take away from SS-1 is that reduction of used electrical energy below $25 \mathrm{MJ} / \mathrm{kg}$ CFRP waste (which is the 
base case value) would lead to environmental and human health gains (the negative side of the yaxis). For example, more energy-efficient pumps and compressors could be used in the SCWbased solvolysis process. It should be noted that the origin point (0\%, 0\%) in Fig. 7 represents the base case energy consumption for solvolysis of $1 \mathrm{~kg}$ CFRP waste, namely: $25 \mathrm{MJ}$ of electrical energy and $145 \mathrm{MJ}$ of thermal energy from NG to produce the required amount of SCW (4.67 kg) for this solvolysis process (Knight, 2013; Dauguet et al., 2015).

The selected sensitivity parameter for SS-2 (Fig. 8) is the thermal energy from NG (145 MJ/kg CFRP waste) used for production of $4.67 \mathrm{~kg}$ SCW required for dissolving of $1 \mathrm{~kg}$ CFRP waste (Knight, 2013; Dauguet et al., 2015).

Fig. 7. Solvolysis sensitivity study SS-1: Percent change in calculated impact categories vs. percent change in electrical energy (Calculations based on $1 \mathrm{FU}$, i.e., $1 \mathrm{~kg}$ CFRP waste).

Legend: 1) Human Health, Particulates [kg PM2.5-Equiv.], 2) Ecotoxicity [CTUe], 3) Acidification [kg SO2-Equiv.], 4) Human toxicity, non-carcinogenics [CTUh], 5) Human toxicity, carcinogenics [CTUh], 6) Ozone Depletion [kg CFC 11-Equiv.], 7) Eutrophication [kg N-Equiv.], 8) Smog [kg O3-Equiv.], and 9) Global Warming [kg CO2-Equiv.]

The x-axis in Fig. 8 represents the percent change in NG energy in the positive and negative directions around the origin point $(0 \%, 0 \%)$. As can be seen from Fig. 13 , the most sensitive impact category to changes in NG energy (line with steepest slope) is global warming [kg CO2-Equiv.] followed by eutrophication [kg N-Equiv.] and human toxicity, carcinogenics [CTUh]. The least sensitive parameter to changes in NG energy (line with lowest slope) is ozone depletion [kg CFC 11-Equiv. The main take away from SS-2 is that reduction of used NG energy (below 145 MJ 
which is the base case value) would lead to environmental and human health gains (the negative side of the y-axis in Fig. 8). For example, use of a more efficient-energy steam boiler would be recommended. It should be noted that the origin point $(0 \%, 0 \%)$ in Fig. 8 represents the base case energy consumption for solvolysis of $1 \mathrm{~kg}$ CFRP waste, namely, $25 \mathrm{MJ}$ of electrical energy and 145 MJ of thermal energy from NG to produce the required amount of SCW for this solvolysis process. Appendix (A) provides more detailed HYSYS simulation model for SCW production.

Fig. 8. Solvolysis sensitivity study SS-2: Percent change in calculated impact categories vs. percent change in electrical energy. Calculations based on $1 \mathrm{FU}$, i.e., $1 \mathrm{~kg}$ CFRP waste.

Legend: 1) Global Warming [kg CO2-Equiv.], 2) Eutrophication [kg N-Equiv.], 3) Human toxicity, carcinogenics [CTUh], 4) Smog [kg O3-Equiv.], 5) Human toxicity, non-carcinogenics [CTUh], 6) Ecotoxicity [CTUe], 7) Acidification [kg SO2-Equiv.], 8) Human Health, Particulates [kg PM2,5-Equiv.], and 9) Ozone Depletion [kg CFC 11-Equiv.].

\subsubsection{Scenarios analysis (SA)}

Comparative environmental and human health impacts assessments have been conducted for three scenarios shown in Table 3. Scenarios 1 and 2 hypothetically assume that improvements have been made to reduce the energy intensity of SCW production by $50 \%$ and $25 \%$, respectively, compared to the base case scenario.

\section{Table 3}

Scenarios analysis for SCW-based solvolysis.

Fig. 9 shows the impacts assessment results for the three scenarios provided in Table 3. The main takeaways from this scenarios analysis are twofold:

a) Environmental and human health gains can be achieved by reducing the energy expenditure in the SCW-based solvolysis below the energy consumption associated with the base case 
scenario. For example, a comparison between scenario 1 and the base case scenario reveals that the highest reduction would be $\approx 49.8 \%$ and correspond to the ecotoxicity category followed by $49.4 \%$ reduction which corresponds to global warming. The lowest reduction is $31.1 \%$ and corresponds to ozone depletion.

b) Comparison of impact categories of SCW-based solvolysis scenarios (Fig. 9) vs. pyrolysis scenarios analysis (Fig. 5) would reveal that even if energy requirement for SCW-based solvolysis can be reduced to $25 \%$ of the energy requirement for the base case scenario (Table 3), the impact categories associated with pyrolysis (whether pyrolyzer's heater comes from electricity or from NG burning) remain below those associated with solvolysis scenarios (Fig. 9). For example, the carbon footprint associated with solvolysis 'Scenario 2' is about 6 times higher than that associated with scenario where pyrolyzer is electrically heated and about 58 times higher than that associated with scenario where pyrolyzer's heat is from NG burning (Fig. 5).

Fig. 9. Scenarios analysis: SCW-based solvolysis.

\subsection{Comparative assessment: pyrolysis vs. solvolysis using SCW}

Qualitative arguments have been made about merits and drawbacks of CFRP waste recycling via pyrolysis versus solvolysis (Keith et al., 2016). For example, a major drawback of pyrolysis is inability to recover the thermoset resin since it is thermally destroyed and, hence, the life cycle loop is not closed. However, potential use of pyrolysis gases as a fuel and use of pyrolysis oils and wax as feedstock for other chemicals could, to some extent, offset the aforementioned drawback. One of the drawbacks CRFP waste recycling via solvolysis, in addition to high cost and energy usage, is that resulting liquid phase (containing organic monomers) represents major health and 
safety hazards if not chemical treated to make other valuable products. Moreover, the presence of organic residue on rCF require additional treatment with chemical solvents (such as acetone) to remover this residue from the recovered fiber (Keith et al., 2016). One of key merits of solvolysis, however, is that the resulting rCF can have mechanical properties close to that of nCF.

This research brings to light new insights by conducting comparative environmental and human safety impacts assessment of pyrolysis (with NG for pyrolyzer's heating) and SCW-based solvolysis for CFRP waste recycling. Results of the carried out comparative impacts assessment are summarized in Fig. 10.

Fig. 10. Percent reduction in impact categories (Eq. 1) as a result of using pyrolysis in lieu of solvolysis for CFRP recycling.

Fig. 10 delineates the percent reduction in impact categories as a result of using pyrolysis in lieu of solvolysis for recycling CFRP waste. The Y-axis in Fig. 15 is calculated using Eq. (1) as follows:

Percent reduction in impact category $=\frac{\left.(\text { Impacts Category })\right|_{\text {solvolysis }}-\left.(\text { Impact Category })\right|_{\text {Pyrolysis }}}{\left.(\text { Impact Category })\right|_{\text {Pyrolysis }}}$ $\ldots(1)$

Eq. (1) has been applied to each of the nine impact categories (shown on x-axis) to calculate the corresponding percent reduction (shown on y-axis). As can be seen from Fig. 15, the percent reduction in impact categories ranges from $62.2 \%$ (lowest) for ozone depletion and up to $98.7 \%$ (highest) for ecotoxicity and human health (particulates). 


\section{Conclusions}

In the present research, comparative environmental and human health impacts assessments have been performed for two recycling technologies of CFRP waste, namely: a) thermolysis via pyrolysis and b) solvolysis using SCW. The former technology was considered a 'base line' for benchmarking purposes with the latter "alternative' technology. Interpretation of LCIA results for the selected recycling technologies included base case scenarios, sensitivity studies, and scenarios analysis. LCIA calculations were based on $1 \mathrm{FU}$, i.e., $1 \mathrm{~kg}$ of CFRP waste. The principal conclusions of this research are four fold: i) The calculated nine impact categories associated with solvolysis are higher than those from pyrolysis (Subsection 4.3 'Comparative assessment: pyrolysis vs. solvolysis using SCW'). For example, human health impact (particulates) category from solvolysis is $\approx 78$ times greater than that from pyrolysis and ecotoxicity from solvolysis is $\approx$ 76 times greater than that from pyrolysis. Carbon footprint (i.e., global warming) from solvolysis is $\approx 17$ times greater than that from pyrolysis and ozone depletion category from solvolysis is $\approx 3$ times greater than that from pyrolysis, ii) Accordingly, the comparative assessment results provided quantitative evidence to support rejection of the research hypotheses $\left(\mathrm{H}_{1,1}\right.$ and $\left.\mathrm{H}_{1,2}\right)$ in favor of the associated null hypotheses $\left(\mathrm{H}_{0,1}\right.$ and $\left.\mathrm{H}_{0,2}\right)$. Details are provided in 'Subsection 3.2,' iii) Use of NG in lieu of electricity for pyrolyzer's heating would lead to $\approx 95.7 \%$ reduction in ozone depletion (highest), followed by $\approx 91.6 \%$ reduction in human health (particulates), and $\approx$ $37 \%$ reduction in ecotoxicity (lowest). The reduction in carbon footprint is $\approx 55.4 \%$ (Subsection 4.1.3 'Scenarios analysis'), and iv) The comparative assessment results provided quantitative evidence that CFRP waste recycling via pyrolysis is more advantageous from environmental and human health perspectives compared to solvolysis using SCW. The aforementioned advantages could be further amplified by: a) Use of pyrolyzer's gaseous recyclate as a fuel to displace some 
of the thermal energy required for pyrolyzer's heating and b) Use of pyrolyzer's oils and wax recyclate as fuels or intermediates for production of other chemicals. Finally, in addition to the ongoing experimental investigations that focus only on identifying the best solvent for the solvolysis technology, it is equally important that future research should consider quantification of the energy intensity as well as environmental and human health impacts of the proposed solvents.

\section{Acknowledgements}

The constructive comments and reviews provided during this research by Professors Richard E. Wetzler and Marshall T. Spriggs of Harvard University, Cambridge, Massachusetts are greatly appreciated. Also, the author would like to thank Susan Killoran, a Fellow Librarian at the Harris Manchester College, University of Oxford, UK, for her valuable assistance during the literature review phase of this search.

\section{References}

Akesson, D. et al. (2012). Microwave pyrolysis as a method of recycling glass fibre from used blades of wind turbines. Journal of Reinforced Plastics and Composites, 31(17), 11361142.

Bjorklund A, Finnveden G. (2005). Recycling revisited life cycle comparisons of global warming impact and total energy use of waste management strategies. J. Resources, Conservation \& Recycling, 44 (4), 309-317.

Bovea, M.D. and Vidal, R. (2004). Increasing product value by integrating environmental impacts, costs, and customer valuation. J. Resources, Conservation \& Recycling, 41 (2), 133-145.

Carberry, W. (2008). Airplane recycling efforts benefit Boeing operators. Boeing AERO Magazine QRT 4.08, 6-13.

Cunliffe, A. et al. (2003). Pyrolysis of composite plastic waste. Environmental Technology, 24, 653-663. 
Das, J. et al. (2016). Global carbon fiber composites supply chain competitiveness analysis. Tennessee, Knoxville: Oak Ridge National Laboratory (ORNL).

Dauguet, M. et al. (2015). Recycling of CFRP for high value applications. Procedia CIRP Life Cycle Engineering, 1-7.

Duflou, J. et al. (2009). Environmental impact analysis of composite use in car manufacturing. CIRP Annals - Manufacturing Technology, 58, 9-12.

Greco, A. et al. (2012). Thermal and chemical treatment of recycled carbon fibres for improved adhesion to polymeric matrix. Journal of Composite Materials, 369-377.

Henry, L. et al. (2016). Semi-continuous flow recycling method for carbon fiber reinforced thermoset polymers by near- and supercritical solvolysis. Polymer Degradation and Stability, 133 , 264-274.

Howarth, J. et al. (2014). Energy intensity and environmental analysis of mechanical recycling of carbon fibre composite. Journal of Cleaner Production, 81, 46-50.

ISO 14040 (2006). International Organization for Standardization. Environmental management - life cycle assessment - principles and framework. Switzerland: ISO14000 International Standards Compendium.

ISO 14044 (2006). International Organization for Standardization. Environmental management - life cycle assessment - requirements and guidelines. Switzerland: ISO14000 International Standards Compendium.

Keith, M. et al. (2016). Optimization of solvolysis for for recycling carbon fiber reinforced composites. ECCM17 - 17th European Conference on Composite Materials, 26-30th, June, (pp. 1-7). Munich, Germany, 26-30th June 2016.

Khalil, Y.F. et al. (2009). Quantifying and addressing the DOE material reactivity requirements with analysis \& testing of hydrogen storage materials \& systems. U.S. Department of Energy, Annual Merit Review (AMR), Paper \# STP-50-Khalil, May 20, 2009, Arlington, VA, 1-30.

Khalil, Y.F. et al. (2010). Quantifying and addressing the DOE material reactivity requirements with analysis \& testing of hydrogen storage materials \& systems. U.S. Department of Energy, Annual Merit Review (AMR), Paper \# ST012, June 8, 2010, Washington, DC.

Khalil, Y. F. (2017). Eco-efficient lightweight carbon-fiber reinforced polymer for environmentally greener commercial aviation industry. Journal of Sustainable Production and Consumption, 12, 16-26.

Knight, C. (2013). Recycling high-performance carbon fiber reinforced polymer composites using subcritical and supercritical water. Ann Arbor, MI 48106 - 1346: UMIT Dissertation Publishing, UMI no. 3596525, ProQuest, LLC. 
La Rosa, A. et al. (2016). Recycling treatment of carbon fiber/epoxy composites: materials recovery and characterization and environmental impacts through life cycle assessment. Composites Part B, 104, 17-25.

Lester, E. et al. (2004). Microwave heating as a means for carbon fiber recovery from polymer composites: a technical feasibility study. Materials Research Bulletin, 39, 1549-1556.

López, F. et al. (2013). Recovery of carbon fibres by the thermolysis and gasification of waste prepreg. Journal of Analytical and Applied Pyrolysis, 104, 675-683.

Loppinet-Serani, A. et al. (2008). Current and foreseeable applications of supercritical water for energy and the environment. ChemSusChem, 1, 486 - 503.

Meng, F. et al. (2017). Energy and environmental assessment and reuse of fluidised bed recycled carbon fibres. Composites: Part A, 100, 206-214.

Morin, C. et al. (2012). Near- and supercritical solvolysis of carbon fibre reinforced polymers (CFRPs) for recycling carbon fibers as a valuable resource: State of the art. J. of Supercritical Fluids, 66, 232-240.

Nunes, A. et al. (2017). Life cycle assessment of a steam thermolysis process to recover carbon fibers from carbon fiber-reinforced polymer waste. Int J Life Cycle Assessment, https://doi.org/10.1007/s11367-017-1416-6, 1-14.

Obunai, K. et al. (2015). Carbon fiber extraction from waste CFRP by microwave irradiation. Composites: Part A 78 (2015) 160-165

Okajima, I. and Sako, T. (2017). Recycling of carbon fiber-reinforced plastic using supercritical and subcritical fluids. J Mater Cycles Waste Manag,19, 15-20.

Oliveux, G. et al. (2015). Current status of recycling of fibre reinforced polymers: review of technologies, reuse and resulting properties . Prog Mater Sci, 72, 61-99.

Pickering, S. (2006). Recycling technologies for thermoset composite materials-current status. Composites: Part A, 37, 1206-1215.

Pimenta, S. and Pinho, S.T. (2011). Recycling carbon fibre reinforced polymers for structural applications: Technology review and market outlook. . Waste Management, 31, 378-392.

Pinçaud, M. et al. (2014). Environmental feasibility of the recycling of carbon fibers from CFRPs by solvolysis using supercritical water. ACS Sustain Chem Eng, 2, 1498-1502.

Pinero-Hernanz, R. et al. (2008). Chemical recycling of carbon fiber reinforced composites in nearcritical and supercritical water. . Composites: Part A 39, 454-461.

Pompidou, S. et al. (2012). Recycling of carbon fiber. Identification of bases for a synergy between recyclers and designers. ASME 2012 11th Biennial Conference on Engineering Systems Design and Analysis. Nantes, France: ASME. 
Robert, T. (2017, November 18). The carbon fiber industry worldwide 2011-2020: An evaluation of current markets and future supply and demand. Retrieved from CarbonFiber.com: http://www.carbonfiber-report.com/Special.pdf

Rybicka J. et al. (2016). Technology readiness level assessment. J Clean Prod, 112, 1001-1012.

Shuaib, N.A. et al. (2015). Resource efficiency and composite waste in UK supply chain. Procedia CIRP, 29, 662-667.

Song, Y. et al. (2009). Life cycle energy analysis of fiber-reinforced composites. Composites: Part A, 40, 1257-1265.

Vicki, P. (2010). Launching the carbon fiber recycling industry. Reinforced Plastics, 54, 33-37.

Witik, R. et al. (2013). Carbon fibre reinforced composite waste: an environmental assessment of recycling, energy recovery and landfilling. Compos A Appl Sci Manuf, 49, 89-99.

Witik, R. et al. (2013). Carbon fibre reinforced composite waste: An environmental assessment of recycling, energy recovery and landfilling. Composites: Part A, 49, 89-99.

Yang, Y. et al. (2012). Recycling of composite materials. Chemical Engineering and Processing, 51, 53-68.

Ye, S. et al. (2013). Parameter optimization of the steam thermolysis: A process to recover carbon fibers from polymer-matrix composites. Waste Biomass Valor, 4, 73-86.

Yildirir, E. et al. (2014). Recovery of carbon fibers and production of high quality fuel gas from the chemical recycling of carbon fiber reinforced plastic wastes. J. of Supercritical Fluids, 92, 107-114.

Yuyan, L. et al. (2009). Recycling of carbon fibre reinforced composites using water in subcritical conditions. Materials Science and Engineering, A 520 , 179-183. 